\title{
Orden social y conflicto en noroccidente de Colombia. Nariño (Antioquia), Riosucio (Chocó) y San Pedro de Urabá, 1991-2010
}

\author{
Local Order and Conflict in Colombian \\ Northwest. Nariño (Antioquia), Riosucio \\ (Chocó) and San Pedro de Urabá, 1991-2010
}

\section{Ordem social e conflito no norocidente da Colômbia. Nariño (Antioquia), Riosucio (Chocó) e San Pedro de Urabá, 1991-2010}

\author{
Clara Inés García ${ }^{2}$ \\ Docente investigadora de la Universidad de Antioquia, Medellín, Colombia \\ cigarciao1@gmail.com \\ Clara Inés Aramburo ${ }^{3}$ \\ Docente investigadora de la Universidad de Antioquia, Medellín, Colombia \\ clara.aramburo@udea.edu.co \\ Juan Camilo Domínguez ${ }^{4}$ \\ Asistente investigación de la Universidad de Antioquia, Medellín, Colombia \\ dominguez.camilo@hotmail.com
}

Recibido: 09/08/2014

Aceptado: $24 / 11 / 2015$

1 Este artículo es producto de la investigación adelantada en el marco del proyecto Órdenes locales en reconfiguración: de regulaciones, acomodos y resistencias en regiones de intenso conflicto violento 1991-2010. Una investigación comparada, financiada por Colciencias y por los tres centros de investigación asociados: INER, de la Universidad de Antioquia, CIDSE, de la Universidad del Valle y CINEP de Bogotá y con el apoyo de la Estrategia de Sostenibilidad 2013-2014 de la Universidad de Antioquia al Grupo Estudios del Territorio de la misma universidad.

2 Socióloga. Diploma de Estudios Superiores Especializados en Políticas Sociales.

3 Antropóloga. Maestría en Ciencia Política.

4 Sociólogo. Maestría en Estudios Socioespaciales. 


\title{
Resumen
}

Este artículo se pregunta cómo se reconfiguraron los órdenes locales en los territorios de mayor confrontación armada en Colombia entre 1991 y 2010, cuáles son los factores que condicionan esas reconfiguraciones y cuál el tipo específico de órdenes locales resultantes. Con base en el concepto de orden social, una tipología construida con el cruce de las categorías de coerción y agencia y un enfoque comparativo inspirado en la configuración compleja de factores explicativos de Charles Ragin, se exponen los resultados que arroja el estudio de los tres casos abordados en cuanto a la reconfiguración de estos tres órdenes locales y a las diferencias más sobresalientes que muestran estas localidades en su capacidad para responder a las condiciones de la confrontación armada.

Palabras clave: órdenes locales; conflicto armado; agencia; coerción.

\begin{abstract}
This paper investigates how local orders were re configured in territories with highest level of armed confrontation in Colombia between 1991 and 2010, what factors determine those reconfigurations, and what specific type of local orders have resulted. Based on the concept of social order, one typology created from the crossing of categories of coercion and agency, and a comparative approach inspired by complex configuration of explanatory factors of Charles Ragin, the article states the results shown by the study of the three cases discussed in terms of the reconfiguration of these three local orders, and the outstanding differences that show these localities in its ability to meet the conditions of armed confrontation.
\end{abstract}

Keywords: local order; armed conflict; agency; coercion.

\section{Resumo}

Este artigo se pergunta como se reconfiguraram as ordens locais nos territórios de maior confrontação armada na Colômbia entre 1991 e 2010, quais são os fatores que condicionam essas reconfigurações, e qual o tipo específico de ordens locais que se derivam. Com base no conceito de ordem social, em uma tipologia construída com o cruze das categorias de coerção e agência, assim como em um enfoque comparativo, inspirado na configuração complexa de fatores explicativos de Charles Ragin, expõem-se os resultados deste estudo sobre os três casos abordados, tendo em vista não só a reconfiguração de essas ordens locais, mas também as diferenças de maior visibilidade, mostrando a capacidade que tem estes territórios para reagir às condições da confrontação armada.

Palavras clave: ordens locais; conflito armado; agencia; coerção.

Este trabajo está bajo la licencia Creative Commons Attribution 3.0

\footnotetext{
¿Cómo citar este artículo? / How to quote this article?

García, Clara, Clara Aramburo y Juan Domínguez. «Orden social y conflicto en noroccidente de Colombia. Nariño (Antioquia), Riosucio (Chocó) y San Pedro de Urabá, 1991-2010». Sociedad y economía, No. 30 (enero - junio de 2016): 353-374.
} 


\section{Introducción}

En las dos últimas décadas se transformaron las condiciones, lógicas y territorialidades del conflicto armado en Colombia lo mismo que los actores y las maneras como las colectividades locales interactúan con ellos. En este artículo nos preguntamos por el tipo específico de órdenes locales que se configuraron en territorios de intensa confrontación armada en el noroccidente de Colombia durante las décadas de 1990 y 2000, y por cuáles son las diferencias y similitudes más sobresalientes que estas localidades muestran en su capacidad para responder a las condiciones de la confrontación armada.

Este artículo comporta un doble interés: el enfoque comparado y su aplicación a los tres casos estudiados, de una parte, y el contraste que muestra frente a las investigaciones que fundan sus explicaciones en relaciones de tipo binario entre los factores considerados. Nuestro enfoque muestra que no se puede pensar en relaciones unicausales entre el tipo de coerción que establecen los actores armados y la agencia de los pobladores que la viven; que la agencia posible es diversa, así sean similares las condiciones de la coerción que se le contraponen o que la agencia puede ser de una misma especie, así sean muy diversas y hasta antagónicas las condiciones de la coerción con las que se interactúe.

Adoptamos el enfoque de la sociología histórica que permite comparar en términos de lo que Ragin denomina "diverse historical outcomes"; pues no es el número de casos, sino su variedad limitada la que impone los límites al rigor explicativo y esto es central a la lógica del método comparativo (Ragin 1987, 1-18). No buscamos relaciones causales simples ni explicaciones totales o universales. Tampoco buscamos análisis de casos que solo se puedan comprender en su sola particularidad, ni tampoco un análisis comparado de variables que expliquen de manera binaria o por continuum de grados las diferencias o similitudes entre los casos. Buscamos, sí, dar cuenta de la complejidad y la diversidad que constituye a los fenómenos socioespaciales, comprendiendo -en cada lugar- la particular configuración de factores (en plural) que permiten dar cuenta del resultado específico que allí se da en términos de orden social, pero sometiendo a cada localidad al estudio de las mismas variables.

Se trata de valernos de dos elementos: la "configuración causal compleja" para explicar el orden social resultante en cada caso estudiado, en la cual los diferentes factores que dan cuenta de cada uno se comprenden en la relación que guardan unos con otros entre sí-en cuanto a la totalidad que forman- (Ragin 2000, 72). Y al mismo tiempo, pensar esas configuraciones complejas según unas categorías analíticas que posibiliten la comparación. Para ello desarrollamos una tipología con base en los conceptos de agencia ${ }^{5}$

5 El concepto de agencia enfatiza las maneras en las cuales los actores sociales se comprometen relacionalmente con los patrones o esquemas de pensamiento, acción y organización preexistentes, e intervienen de manera más o menos imaginativa sobre los contextos estructurales en que actúan. Se refiere a ese momento de esfuerzo, de selección activa de repertorios según los retos que las situaciones del contexto les formulan a los actores y según las constricciones que el contexto relacional-temporal plantea (Emirbayer y Mische, 1998). 
y coerción ${ }^{6}$. Estos nos dieron la pauta para identificar cada orden local a partir de las formas de interacción que establecen los actores armados y pobladores. Para los contextos de conflicto armado en general, proponemos cuatro formas posibles de agencia: sometimiento, acomodo, solidaridad y resistencia; y dos de coerción: la armada y la política. Del cruce de estas formas de interacción entre agencia y coerción se obtienen ocho tipos posibles de orden local7. Como factores explicativos que en su diversa combinación dan cuenta del resultado -tipo de orden local- estudiamos: 1) la forma económica predominante en la localidad; 2) las identidades sociales preponderantes, con énfasis en aspectos de clase, étnicos o transculturales; 3) la forma predominante de la acción colectiva, ya sea rutinaria, contenciosa o combinada; 4) la forma dominante de presencia del Estado, directa o indirecta; 5) los rasgos centrales del conflicto armado: actor predominante, función que juega el territorio, rasgo de la presencia armada y rasgo de inserción en la sociedad; y 6) los contextos y oportunidades que juegan en la localidad.

\section{Los órdenes sociales reconfigurados}

¿Cómo se reconfiguraron los órdenes locales del municipio de Nariño (Antioquia), Riosucio (Chocó) y San Pedro de Urabá (Antioquia) durante los años 19912010 y cuál fue el tipo de orden que predominó? Describiremos a continuación las respectivas interacciones identificadas como predominantes entre la agencia y la coerción en cada uno de los tres casos analizados.

\subsection{Nariño (Antioquia) o el orden de resistencia con coerción política}

Con la llegada de las FARC a la zona de Nariño a inicios de la década de 1990 comenzó a reconfigurarse el orden social sustentado hasta entonces en una población periférica de campesino tradicional inserto en las redes clientelares del Partido Conservador. Entre 1995 y 2006 las FARC tuvieron una importante presencia local.

A su llegada a la localidad, las FARC se ubicaron en el cañón del río Samaná sur (borde oriental) en límites con el departamento de Caldas (municipio de Samaná, corregimiento de Florencia) de donde se expandieron hacia el sur (corregimientos de Pueblo Nuevo y Arboleda -Pensilvania, Caldas- y Puerto Venus -Nariño-). Allí realizaron las primeras y pocas acciones militares en 1995 contra la Policía Nacional, que lograron evacuarla de las estaciones de Puerto Venus, Pueblo Nuevo, Florencia y Nariño, controlar la zona en el año 2000, expandir su

6 La coerción la entendemos como el ejercicio propio de la autoridad o autoridades y que tiene variaciones desde el uso directo de la fuerza emergentes o la violencia, hasta el ejercicio estrictamente político de la autoridad (Tilly 1994, 44-45; Bourdieu 1999, 224-225). Se aplica al Estado cuando ejerce efectivamente la autoridad en el territorio, y a los propios actores armados ilegales cuando regulan lo fundamental de la vida local.

7 El desarrollo teórico y metodológico de este enfoque y su aplicación a nueve casos locales en diversos puntos cardinales de Colombia se desarrollan en dos artículos separados: Orden local y conflicto: resultados de una metodología comparada en nueve localidades de Colombia (García et al. 2014a) y Órdenes locales y conflicto armado. Una metodología comparada (García et al. 2014b). 
corredor de movilidad entre el Magdalena Medio, Chocó y el centro de Antioquia, y establecer una retaguardia militar durante la década de su presencia. La población rural convivió con las FARC hasta el 2004, época de mínima e intermitente presencia del Ejército que apenas sobrepasaba la zona urbana. Incluso, con la toma violenta que hizo las FARC del casco urbano en 1999, la Policía Nacional se retiró y dejó desprotegida la población durante once meses. La fuerza pública regresó de manera permanente en julio de 2006.

Las FARC establecieron los principales campamentos del Frente 47 en las cumbres de las montañas (más de $3.000 \mathrm{msnm}$ ), utilizaban las tierras medias para tránsito y provisión de vegetales y animales de las parcelas, y extorsionaban y secuestraban a los dueños de las fincas ganaderas ubicadas en las tierras cálidas. En las zonas altas de retaguardia mantuvieron la mejor relación con la población local alentando el proceso organizativo comunitario sin interés ideológico en formar liderazgos comunitarios; en más de una década la comunidad no desarrolló empatía ideológica con la guerrilla aunque los pobladores le reconocen haber mejorado la dinámica comunitaria ${ }^{8}$. De ahí que definamos el tipo de coerción que ejercieron las FARC de manera predominante como coerción política (COP), sin el ejercicio de una violencia explícita y sistemática contra la población y con algún tipo de acción que la población asumiera como beneficiosa.

La coerción armada solo fue ejercida en el casco urbano en la coyuntura en que se lo tomaron (1999-2000). Para la toma se valieron de un carro bomba y la destrucción de varias cuadras del centro urbano. Durante su dominio ejercieron el cobro impositivo a locales comerciales, ancianato, hospital, secretarías municipales, utilizaron el coliseo cubierto para interrogatorios, agredieron mediante insultos, no pagaron cuentas en cantinas y restaurantes, asesinaron selectivamente -incluido el personero- y restringieron el ingreso y salida de la población. Tales agresiones detonaron un proceso de resistencia impulsado por líderes locales, en su mayoría miembros de la Unidad Municipal de Asistencia Técnica Agropecuaria (UMATA), quienes comenzaron a manifestar su posición, instalando pañuelos blancos o negros en diferente lugares del pueblo como símbolo de paz o duelo; llegaron a cerrar el comercio en rechazo a las acciones militares, a los intentos de secuestro masivo o a los asesinatos selectivos. Y cuando se sintieron más fuertes, convocaron a dos asambleas locales para pedirles a los jefes guerrilleros límites en su accionar armado?.

Tras la retirada de las FARC del casco urbano en el 2000 (pero su permanencia y dominio en toda la zona rural), el grupo de resistentes inició un proceso de organización político-partidista para recobrar control sobre la organización comunitaria y frenar la exacción económica de recursos públicos del actor armado, y disputar electoralmente la Alcaldía a la élite local y reorientar la modalidad del ejercicio del poder local bajo pautas participativas y más democráticas. Bajo el eslogan "Participando con Tod@s por Nuestro Pueblo" el grupo llegó a la Alcaldía y al Concejo en las elecciones del 2003 logrando la representación de los

8 Información recogida en entrevistas a campesinos en las veredas, 2012.

9 Información recogida en la serie de entrevistas realizadas en trabajo de campo durante 2009, 2010 y 2012. 
ocho centros zonales en el Concejo como desafío a viejos esquemas clientelares discriminatorios sobre ciertos territorios y reorganizando la división político administrativa en Centros Zonales y la organización poblacional en Comités de Concertación Comunitaria-Copacos-.

Este sistema de participación comunitaria en asambleas veredales, zonales y municipal, centrado en la elaboración y control del presupuesto municipal, democratizó la representación política territorial y la toma de decisiones sobre la inversión pública, sustituyó la acción de la vieja élite política local y desmontó el discurso de las FARC para presionar a los líderes de la acción comunal y a los funcionarios públicos en el direccionamiento de los recursos. La organización comunitaria se vinculó estrechamente con la política y fue base electoral de dos elecciones locales sucesivas. Al terminar la confrontación Ejército Nacional y FARC en 2008 , la resistencia mutó y se convirtió en pieza fundamental para labores institucionales de posconflicto. Este sistema de asambleas se mantuvo entre 2003 y 2010. Los Copacos se mantienen hoy como espacio de líderes de las juntas de acción comunal.

\subsection{Riosucio (Chocó) ${ }^{10}$ o el orden de resistencia con coerción armada}

Esta localidad de poblamiento interétnico ${ }^{11}$ permaneció como periferia selvática y aislada durante buena parte del siglo $\mathrm{XX}^{12}$. El Estado delegó en otros actores las funciones de socialización y regulación económica ${ }^{13}$ y solo en las últimas décadas del siglo XX irrumpieron procesos que comenzaron a articular mínimamente dicho territorio con las redes y los conflictos del orden nacional: en los años de 1970 y 1980 las Acciones Comunales entroncan con clientelas y partidos políticos; las compañías madereras intensificaron la explotación forestal bajo nuevas tecnologías, formas jurídicas y corruptelas; las guerrillas (ELN y FARC especialmente) se insertaron en este territorio que asumieron como retaguardia; y las primeras organizaciones campesinas e indígenas fueron impulsadas por los misioneros claretianos.

En 1996 y 1997 se desencadenó de manera intempestiva la confrontación armada en el Bajo Atrato, y a partir del desplazamiento masivo y la desocupación de cuencas que produjo, el orden local se transformó. Cuando la población retornó en medio de la confrontación, tuvo que asentarse y organizarse bajo modalidades inéditas. Se reconfiguraron las formas del asentamiento y las identidades sociales, la organización social y política de sus pobladores, la presencia del Estado y las redes que la población estableció con actores de otras escalas

10 Incluye al hoy municipio de Carmen del Atrato que en el 2000 se desprendió de Riosucio.

11 Afrocolombianos 81,2\% e indígenas 12,8\% (DANE 2005a y 2005b).

12 La desarticulación con las dinámicas nacionales se expresa en: el poblamiento (hasta 1970) procedente exclusivamente del ámbito regional y de comunidades dispersas a lo largo de las cuencas; tejido social basado en ayuda mutua, redes parentales, acatamiento a la autoridad patriarcal y matriarcal afro y autoridades indígenas; economía de autosubsistencia.

13 En los misioneros claretianos (Prefectura Apostólica 1909) y en las compañías madereras que con el Decreto 645/1900 y hasta los años de 1970 tuvieron la potestad, a través de concesiones, para regular la circulación y uso de los recursos forestales y los asuntos laborales (Del Gatto 2008, 23). 
socioespaciales. ¿Cuáles son las características básicas de este nuevo orden local? ¿Qué clase de agencia se desarrolla frente a una coerción armada sostenida y especialmente violenta?

Antes del estallido de la confrontación militar en el Bajo Atrato con la Operación Génesis adelantada por el Ejército Nacional, los 27.666 habitantes (1993), dispersos en un área de $10.376 \mathrm{~km}^{2}$, convivían pacíficamente con las guerrillas FARC y ELN asentados allí en los años de 1980. Estos grupos crearon lazos parentales con la población, realizaron trabajo político con líderes comunitarios y jóvenes del liceo de la cabecera de Riosucio (muchos se enrolaron en las milicias) y reorientaron las acciones comunales y la organización campesina que, respectivamente, habían sido impulsadas por la administración local y los misioneros claretianos. Cuando el Ejército Nacional inició la Operación Génesis (finales de 1996), coordinada con la Operación Cacarica paramilitar ${ }^{14}$ contra las guerrillas, la confrontación entre ejércitos fue marginal; predominó el ataque masivo y violento contra la población civil - sospechosa de ser base social de las guerrillas- a través de bárbaras modalidades de violencia y control a la circulación de personas y mercancías. Las guerrillas, por su parte, asesinaron "sospechosos", líderes que rehusaron hacer "mandados" (alimentación y medicinas), se apropiaron de tiendas comunitarias y comida. Los paramilitares extendieron su control apropiándose ilegalmente de territorios colectivos donde cultivaron palma africana y ofrecieron trabajo a quienes lo aceptaran, repoblaron con mano de obra de confianza y organizaron cooperativas. En el sector tradicional de la madera extendieron su control sobre aserraderos y comercialización e hicieron el Plan Motosierra ${ }^{15}$ para explotar el recurso de las comunidades en las cuencas. Con las compañías madereras reprodujeron -igual que antes las FARC- el cobro de "impuestos" al cultivo y transporte del recurso y controlaron espacios institucionales locales con la "parapolítica". En 2006, cuando se entregó el bloque Élmer Cárdenas, los que permanecieron se reconvirtieron en "Bacrim" y extendieron el cultivo de coca de manera conjunta con las FARC: estas impulsaron y protegieron el cultivo y aquellas lo comercializaron, ante la mirada estupefacta de los pobladores que creían padecer una guerra a muerte entre enemigos: guerrillas y paramilitares. Continuaron los asesinatos, "muertes ejemplarizantes", secuestro de aserradores "sospechosos"; el modelo de control de la economía aplicado por el bloque Élmer Cárdenas, amenazas y persecución a las Zonas Humanitarias, presiones armadas a las comunidades, impedimentos al usufructo de territorios colectivos no recuperados, rearme de las FARC, paros armados, control a la circulación,

14 “...justo el mismo día que el Ejército comenzó a penetrar la zona, las ACCU iniciaron la que ellos llamaron la 'Operación Cacarica', una fase de su avance hacia el sur del Urabá chocoano a través del cual se pretendía hacer presencia en un amplio sector de los caños Cacarica, Salaquí, Truandó y Perancho para enfrentar a las FARC y disputarles el territorio..." Doce paramilitares fueron guías del ejército en la Operación Génesis: 'El Alemán' (Verdadabierta.com s/f).

15 “Según el 'Alemán', "la industria maderera del Atrato fue nuestra alma”. El bloque Élmer Cárdenas custodiaba y supervisaba el negocio maderero de la región de donde obtenía parte de su financiación. La región habla del 'Plan Motosierra' para referirse a las 87 que entregaron los paramilitares a aserradores hacia el 2004 para trabajar en el corazón de la selva. Los equiparon con mulas, gasolina y víveres (Semana.com 2006). 
entre otras estrategias de control armado territorial ${ }^{16}$. En definitiva, la coerción que padeció la población del Bajo Atrato fue claramente una coerción armada (COA), esto es, "aquella que utiliza como medio de dominio las armas y ejerce una violencia deliberada" (García et al. 2014b, 9).

La resistencia de los pobladores se desplegó desde el inicio mismo de la confrontación. Entendemos por resistencia "la agencia que articula prácticas prioritariamente no violentas dirigidas a socavar el poder del que domina y ejerce la violencia, a obtener un propio sentido de control desafiando el miedo a reparar y recrear los elementos de cultura e identidad golpeadas o destruidas por la violencia como método para aplastar la voluntad y buscar soluciones a las deprivaciones de la guerra y al conflicto social" (García 2004, 108).

Desde su origen se diferenciaron las modalidades, orientación política y espacialidades de las resistencias desplegadas en el Bajo Atrato. a) "Los Encaletados", grupo de pobladores de Curvaradó-Jiguamiandó, se negó al desplazamiento; para protegerse cavaron refugios en lo profundo de la selva-cambiándolos de lugar con la frecuencia que obligaban los embates de la guerra- y se alimentaron de raíces y frutos silvestres; y cuando resolvieron visibilizarse cuatro años después (2000) acompañados por agencias internacionales, rechazaron "la neutralidad" sugerida por las Comunidades de Paz de su zona. En el 2003 se disolvieron como organización y se integraron al Consejo Comunitario Mayor del Curvaradó-Jiguamiandó. b) "Las Comunidades de Paz", nacidas en el campamento de desplazados de Pavarandó de la negociación con el Estado y los actores armados, se asentaron en el eje central del río Atrato entre las poblaciones de Curvaradó y Riosucio (Comunidades de Paz San Francisco de Asís, Natividad de María y Nuestra Señora del Carmen). Estuvieron acompañadas por el CINEP, la Diócesis de Apartadó y los misioneros claretianos. El nuevo patrón de asentamiento se organizó en función de la seguridad: concentración urbana cerca de las desembocaduras de los principales ríos, vida cotidiana basada en salidas diurnas a laborar la tierra y bosques circundantes, y defensa, muchas veces infructuosa, de una posición de "neutralidad"17 e inviolabilidad de su territorio frente a los actores armados. En el 2003 se disolvieron ante la imposibilidad de sostener "la neutralidad" por las continuas entradas de miembros de las FARC a sus asentamientos, mediadas por la solidaridad de parientes que formaban parte de las comunidades ${ }^{18}$. Impulsaron la constitución de la Asociación de Consejos

16 Esta panorámica general de actos violentos según actores es resumen de la sistematización de información realizada en la investigación con base en las fuentes: Defensoría del Pueblo (2002); Comisión Intereclesial de Justicia y Paz, Banco de Datos (2008); ODDR (2010); Eltiempo.com (1997); Semana.com (2010); Caracol.com.co (2010); Radiosantafe.com (2009).

17 “...No participar en forma directa ni indirecta en el conflicto armado; no portar armas de fuego; no brindar ayuda táctica, logística y estratégica a ninguna de las partes en conflicto (alimentación, vivienda, refugio, combustible, transporte, mensajería, guardar armas o implementos bélicos)" (Defensoría del Pueblo 2002, 5).

18 "El que fue alcalde de ahí era uno de los líderes, Fredy Robledo y el comandante que llegó ahí era sobrino de Fredy; entonces Fredy le dijo: bueno o te vas de aquí o te levanto a palo, entonces le dijo el guerrillero: bueno tío, levánteme a palo pues y tiró el fusil ahí, levánteme a palo, levánteme... Yo vi esa escena, y entonces: cogió, no discutieron más así como discutimos los chocoanos, no discutieron más, él cogió su fusil y cogió para allá, Fredy salió para allá a tomar y ya; se acabó y los milicianos se quedaron a la orilla del río tomando, ahí se acabó la comunidad 
Comunitarios del Bajo Atrato (Ascoba) y se integraron a ella. c) "Las Zonas Humanitarias"; inicialmente (2000) se constituyeron dos al norte, en Cacarica, acompañadas por la Comisión Intereclesial de Justicia y Paz (negociadas en el campamento de desplazados de Turbo). Acogieron también el patrón de asentamiento concentrado, pero lo complementaron con un proyecto de resistencia más radical al de las Comunidades de Paz: plantearon posiciones más críticas frente al Estado al rehusar el lema de "la neutralidad" y promover "la autonomía"; utilizaron el símbolo del cerramiento de los asentamientos y acudieron a organismos de justicia internacional para presionar al Estado ante lo que consideraron su periódica violación a los derechos humanos y sus omisiones frente a las violencias perpetradas por actores armados y empresarios privados. Entre el 2004 y el 2006, una vez salido el CINEP y disueltos Los Encaletados, se crearon ocho Zonas Humanitarias en el Curvaradó-Jiguamiandó. d) Los Consejos Comunitarios creados por la Ley 70 de 1993 -antes del estallido de la disputa armada y del desplazamientofueron implementados en su mayoría con posterioridad al desplazamiento masivo de la población del Bajo Atrato. Se convirtieron en herramienta clave para defender los derechos territoriales de la población frente a los actores armados, las compañías legales e ilegales explotadoras de recursos y el propio Estado, al erigirse en condición jurídica para cualquier reclamo por la posesión del territorio, la regulación de su explotación y la salvaguarda de los derechos étnicos. Fueron, por tanto, el marco jurídico para el asentamiento de Comunidades de Paz y Zonas Humanitarias, lo mismo que para integrar a los disueltos Encaletados y Comunidades de Paz, y para luchar contra todos los que violentaran los derechos colectivos mediante armas y argucias. Estos actores fueron sustento jurídico de las otras formas de resistencia, al tiempo que se convirtieron ellos mismos en actores de resistencia. En la vida cotidiana sus líderes, como autoridades reconocidas, median y mantienen los límites ante presiones y atropellos que siguen ejerciendo los actores armados. $\mathrm{Al}$ mismo tiempo le dieron a la población afrocolombiana bases para establecer su interlocución con el Estado, marcos institucionales para actuar colectivamente y relacionarse con los demás actores en el territorio. No obstante, esta organización está sujeta a las fragmentaciones y tensiones políticas que dinamizan las diversas modalidades de resistencia, tensiones aumentadas por empresarios madereros y palmeros que tratan de dividirla aún más en un forcejeo por ganar adeptos afrocolombianos para sus proyectos económicos y de apropiación del territorio. Ascoba recoge el 65\% de los consejos; el 35\% restante se divide entre quienes simpatizan con las Zonas Humanitarias y quienes simpatizan con otras tendencias.

\subsection{San Pedro de Urabá o el orden de acomodo con coerción política}

La vida cotidiana de San Pedro de Urabá fue trastocada por dos hechos que cambiaron el orden social local: la llegada de Fidel Castaño en 1988 a Tierralta,

de paz Natividad de María, porque ahí estaba un hermano" (entrevista a Julia Marín, 2012). 
Córdoba y sus alrededores, y la desmovilización del EPL en 1991, que alentó a las FARC y a una disidencia EPL ("Francisco Caraballo") a copar los territorios "despejados" y a declarar objetivo militar a los excombatientes por traición a la revolución en una zona donde comenzaba a señorear Fidel Castaño ${ }^{19}$. Se generaron índices de violencia jamás vistos al norte de Urabá, con una curva en ascenso desde 1991 hasta 1993 y en descenso hasta casi cero en 1996, cuando las FARC fueron expulsadas por los paramilitares del norte. Esta curva recomenzó su ascenso con la desmovilización de las autodefensas en el 2006, y la reconversión de algunos de sus integrantes en miembros de distintas bandas criminales que disputan la cadena del negocio del narcotráfico.

Lo agresivo de la disputa se argumenta en la modalidad, intensidad y nuevas alianzas para las acciones armadas. Fidel Castaño ingresó al territorio con su cuerpo de seguridad privado (propio de una organización patronal) con el que desplegó una intensa violencia contrainsurgente ${ }^{20}$. Buscó obediencia inmediata atemorizando a la población y neutralizando a la guerrilla, difundiendo el lema de acatar al nuevo fusil o sufrir una violencia inimaginable (Cívico 2009, 94). De otro lado, la alianza FARC-disidencia EPL intensificó y aumentó las acciones militares, demostró su fortaleza con la toma de San Pedro de Urabá en 1994 y desató la intervención paramilitar. La violenta confrontación entre viejos y nuevos actores, desembocó en la rendición de la disidencia EPL (corregimiento de El Tomate, San Pedro, en 1996) y en la expulsión definitiva de las FARC de la zona en 1996-1997, lo que marcó el fin de una etapa bélica y despejó el camino para un nuevo orden en el que los paramilitares pasaron de la coerción armada a la política y en el que los pobladores se acomodaron a los métodos paramilitares para mantener a raya a las FARC siempre en asedio, por las que sentían verdadera aversión en un territorio societal EPL.

En esta fase, los paramilitares comenzaron a configurar la retaguardia estratégica y el asiento del campamento de mando de su proyecto nacional paramilitar, contando con la ubicación de San Pedro al pie de la serranía del Abibe y la articulación del occidente y el golfo de Urabá con el norte y el centro del país. Ser retaguardia paramilitar requirió controlar la población, buscando su adhesión de distintas formas pero contando con su beneplácito al haber expulsado del territorio a las FARC. La población aceptó la alianza desmovilizados-paramilitares, en tanto significaba protección a los desmovilizados EPL; se trataba de mantener una lealtad a quienes representaban los ideales de un campesinado militante por tradición, verdadera guerrilla societal nacida en la década de 1960 en la Serranía del Abibe ${ }^{21}$.

La adhesión paulatina de la población al proyecto paramilitar se dio en la medida en que la protección contra las incursiones FARC fueron más efectivas, en que la coerción armada disminuyó (una vez asesinaron o expulsaron a campesinos y hacendados inconformes) y en que aumentaron los reclutamientos de pobladores (excombatientes EPL o no) a su ejército. También, en la medida en que el ejército privado de Fidel Castaño hizo cambios en las estrategias militares y reforzó las

19 Luego llegaron Carlos y Vicente Castaño.

20 Llamados Los Tangueros por la finca Las Tangas en Tierralta donde se asentó Fidel Castaño.

21 EPL y FARC convivieron como grupos insurrectos durante las primeras etapas en Urabá. Con el tiempo desarrollaron antipatías nacidas de la intromisión FARC en territorios EPL al fundar en 1970 el $5^{\circ}$ Frente en la Serranía del Abibe, que se agudizaron cuando le disputaron la clase trabajadora en el eje bananero y se mostraron al rojo vivo cuando persiguieron a los desmovilizados. 
estrategias políticas y sociales. En 1995 crearon la estructura Autodefensas Campesinas de Córdoba y Urabá con control en el norte de Urabá y el eje bananero; ese año ampliaron el control hacia Chocó y sur de Urabá con el frente Élmer Cárdenas, y dos años más tarde unificaron los distintos frentes del país en las Autodefensas Unidas de Colombia (1997), oficializaron las reglas del juego en un manual de principios y procedimientos, definieron pautas de comportamiento y militarmente consolidaron un ejército capaz de revertir cualquier simpatía insurgente, obtener silencio y respaldo forzado (Cívico 2009, 227). Se configuraron como autoridad obedecida por los pobladores.

En ese momento desplegaron una estrategia social alternativa, consistente en una "minirreforma agraria" o repartición de tierras (de las arrebatadas y compradas a engaño) ${ }^{22}$ para buscar aliados, mejorándoles las condiciones de vida y estructurando una cadena de apoyos para infiltrar, controlar y manejar los liderazgos. También trajeron nuevo personal en remplazo del campesinado despojado, sustituido en sus pequeñas parcelas y porciones de tierra que cultivaban en los bordes de las haciendas bajo la modalidad de préstamo y arriendo, práctica tradicional de las sabanas de Córdoba y norte del país.

Aunque este proyecto campesino se vino abajo luego - con Vicente Castaño- demostró su potencia con formas como la ONG llamada Asocomún, premiada nacional e internacionalmente, y en el aliento al trabajo rural con la creación de cooperativas, precooperativas, asociaciones de mujeres, de jóvenes; "fueron alrededor de 23 cooperativas"23. Asocomún también acompañó programas institucionales como Familias Guardabosques (2004) y mantuvo activa la participación campesina local. Logró convertirse en una empresa prestadora de servicios certificada, luego asesora de municipios Epsagro y más tarde OGA (Organización Gestora Acompañante) ${ }^{24}$.

Con los hacendados ocurrió lo mismo que con los campesinos: fueron sacados por terratenientes paramilitares y narcotraficantes que compraron a la fuerza o robaron sus tierras; o se quedaron bajo condiciones impuestas o apoyando y financiando el proyecto. Pero llegaron del Valle los nuevos narcoparas ${ }^{25}$ (como los nuevos propietarios de frentes paramilitares, negociados como franquicias por Vicente Castaño en 1998) y con apetito por la tierra al estilo mafioso ${ }^{26}$. Desde entonces, dejaron de financiar la guerra con la extorsión y cobro de cuotas a cambio de seguridad, y le cambiaron de uso a la tierra: ganado de fachada para camuflar la actividad del narcotráfico, centros de adiestramiento de combatientes en las fincas ${ }^{27}$, de tortura de enemigos y enterramiento de cuerpos en fosas comunes.

22 "A finales del año 90, Fidel decidió - dentro de unas negociaciones de paz que estaba haciendo el EPL con el gobierno- aportar desmovilizando su fuerza, entregando las armas y además entregando a los campesinos desplazados 10.000 hectáreas de las mejores tierras del valle del Sinú, que son las mejores tierras cultivables de Colombia" (Cívico 2009, 201).

23 Entrevista a líder de Asocomún de nombre reservado. San Pedro de Urabá, 2008.

24 Información recogida con nombre reservado en entrevistas a gestores de la ONG en la cabecera de San Pedro. Julio de 2010.

25 Doblecero los denomina "purasangre" y "narcoparas" (Cívico 2009, 260), y se configuran cuando se incorpora el narcotráfico a su guerra y se genera la división interna entre "purasangres" o paramilitares de corazón.

26 A los narcos del Valle no les gusta finca chiquita (Cívico 2009, 67-69).

27 Fincas La 21, La 35, La Acuarela; esta era sede de la Escuela de Comandos de las Autodefensas (Vélez 2006). 
Los hacendados y campesinos tradicionales perdieron toda presencia y poder local en la medida en que la vida cotidiana quedó controlada, vigilada y regulada en un territorio de retaguardia. También, en la medida en que se permearon las instituciones dada la relativa facilidad que ofrecía el control de una población rural pequeña y dispersa, de bajo perfil político, escaso caudal electoral comparado con el resto de municipios de la región, y poca injerencia en las decisiones regionales. Si bien San Pedro quedó por fuera del proyecto de control político "Urabá Grande Unido y en Paz"28 diseñado para los municipios de mayor caudal electoral del norte y del eje bananero, Fredy Rendón Herrera, alias "El Alemán" ideó uno semejante llamado Pacto "Marizco"29 para los poblados de la margen izquierda del rio Sinú que incluyó a San Pedro en Antioquia (y a los poblados de Córdoba: Canalete, Los Córdobas, Puerto Escondido y Moñitos) y a partir del cual las instancias locales del Estado, los liderazgos en las Juntas de Acción Comunal, la Alcaldía, el Concejo y las decisiones locales de San Pedro fueron penetradas.

Los fenómenos descritos ilustran un proceso de transformación del orden social que comenzó con una fuerte coerción armada y estrategias de terror y pasó a otras formas de relacionamiento político entre paramilitares y población local hasta configurar un orden que actuó entre 1997 (expulsión de las FARC) y 2006 (desmovilización paramilitar). En este nuevo orden, los paramilitares ejercieron poder sin violencia explícita, fueron reconocidos como autoridad, obedecidos por interés instrumental y beneficio de algunas de sus regulaciones, es decir, hubo un acomodo pragmático que significaba más que sometimiento pasivo pero menos que solidaridad e identidad ideológica con el nuevo orden establecido.

\section{Comparaciones}

Los tres casos estudiados aquí pertenecen entonces a tres tipos diferentes de orden local, tal como se puede apreciar en la tabla 1.

Tabla 1 . Tipos de orden local

\begin{tabular}{|c|c|}
\hline Casos locales & Tipo de orden social agencia/coerción \\
\hline San Pedro de Urabá & $\begin{array}{c}\text { ACOP } \\
\text { Acomodo/Coerción política }\end{array}$ \\
\hline Riosucio (Chocó) & RESCOA \\
& Resistencia/Coerción armada \\
\hline Nariño (Antioquia) & RESCOP \\
& Resistencia/Coerción política \\
\hline
\end{tabular}

Fuente: elaboración propia.

28 Proyecto gestado a finales del 2001 por orden de Carlos Castaño, quien convocó a una reunión en la finca La 21 (San Pedro de Urabá) para definir una estrategia para la campaña al Senado y la Cámara de Representantes 2002-2006 buscando obtener escaños en el Congreso, cosa que lograron con un escaño en la Cámara.

29 Funcionarios de Córdoba aceptaron nexos con alias "El Alemán”. Reconocieron haber participado en el Pacto de Marizco con el cual se apoyó el proyecto político paramilitar en el departamento (Elespectador.com 2012). 
Estudiosos de la relación entre las formas de inserción en el territorio o de violencia ejercidas por los actores armados y el comportamiento de los pobladores en las zonas que los padecen suelen plantear la cuestión de alguna manera dicotómica. Por ejemplo, Ana Arjona, cuando explica las variaciones de los órdenes sociales en zonas de conflicto armado, afirma que "la resistencia colectiva, la cual es más frecuente cuando las instituciones pre-existentes son más legítimas y eficaces" (s/f, 9), y en los casos donde el orden instaurado por un grupo armado con un alto grado de intervención en todos los ámbitos de la vida social -"rebelocracia"- solo hay resistencia colectiva en aquellas comunidades con alta calidad institucional preexistente. Por su parte, Statis Kalyvas (2008) afirma, con referencia al tipo de control territorial de los grupos armados y a la colaboración o no de los civiles, que el grado de control que establezca el grupo armado guarda relación directa con el grado de la colaboración que recibe o no por parte de la población, y establece un continuum, desde situaciones de dominio de los armados con poco ejercicio de la violencia que se asocian con una alta probabilidad de colaboración de la población para el que domina, hasta situaciones de soberanía fragmentada donde los actores que ejercen violencia obtienen una baja probabilidad de colaboración de la población.

Los tres casos analizados en este artículo - lo mismo que el conjunto de los nueve que sometimos a la comparación general en artículo citado al comienzo (García et al. 2014a)- nos muestran una situación mucho más diversa en la combinación de los factores que definen el tipo de relación entre la acción de los armados y la de los pobladores.

Si pensamos que las agencias de "acomodo" pueden estar cercanas a la "colaboración" definida por Kalyvas (2008) y las agencias de "resistencia" a las de "no colaboración", podemos sustentar que los resultados de nuestra investigación muestran una cosa distinta a lo planteado por este autor; pues las resistencias o los acomodos (menores o mayores niveles de colaboración de la población) no están asociados a determinadas condiciones de control del territorio (disputa o dominio) o de nivel de violencia (mayor o menor) ejercidos por parte de los actores armados. Resistencias y acomodos se presentan tanto en condiciones donde predomina el uso violento de las armas contra la población como donde esto no sucede; en condiciones de dominio de un actor armado, así como donde ninguno tiene el dominio o la soberanía es fragmentada. De otra parte, y en contraposición a los planteamientos de Arjona, si pensamos en localidades resistentes, estas se presentan en localidades con y sin condiciones preexistentes de legitimidad y eficacia institucional.

Para sustentar esto nos apoyamos en dos conceptos expuestos al comienzo de este artículo: el de la "configuración causal compleja", o sea que siempre son una pluralidad de factores combinados los que condicionan un resultado determinado; y el concepto de agencia de Emirbayer que abre -frente a cualquier contexto espacial-temporal-relacional- un abanico de posibilidades variadas que se define en cada lugar según sean los recursos del pasado, del presente y/o del futuro que los actores retomen de sus propias memorias, de los contextos de oportunidad que el entorno plantee y de sus capacidades para innovar. Esa es la característica de la agencia: ser potencial de infinitas posibilidades, según los elementos del pasado, el presente o el futuro que los actores combinen en sus 
prácticas para responder a los retos planteados por el contexto histórico en el que se insertan (Emirbayer y Mische 1998).

Con base en ello analizamos a continuación nuestros casos de estudio en función de los factores que explican en cada uno el resultado de la combinación entre agencia y coerción, para sacar al final las conclusiones pertinentes relacionadas muy directamente con el enfoque propuesto en este escrito.

\subsection{Nariño (Antioquia)}

En Nariño la resistencia tiene dos momentos. El primero, emerge como "acción directa" en la coyuntura en que las FARC se toman la cabecera municipal y la Policía abandona el pueblo. Son fuerzas exclusivamente locales las que la orientan y con sus repertorios (actos simbólicos, cierres de comercio, manifestación en la calle, asamblea y llamado al diálogo a los guerrilleros) expresan públicamente su rechazo a los actos violentos y su capacidad de retomar - aunque pasajeramente- espacios públicos y la palabra. Cuando las FARC se retiran a la zona rural, la resistencia adopta otra modalidad con acciones articuladas en "programas constructivos" de más largo aliento (García 2013). Tal fue el movimiento político alternativo que logra sustituir a la vieja élite local, democratizar las formas de hacer política en la localidad y neutralizar las presiones de las FARC por la orientación de los recursos públicos en las veredas. ¿Qué combinación de factores permite explicar la resistencia en Nariño?

El carácter del territorio - corredor de movilidad y zona de retaguardia para las FARC, sin que otro actor armado le disputara el control- hizo que la coerción predominante fuera más política que armada. Esta condición, en términos de la teoría desarrollada por autores como Kalyvas, impulsaría agencias tendientes más al acomodo o la colaboración con los armados. Pero así no fue. Entonces, ¿qué factores explican la resistencia? Fueron tres los factores que, en conjunto, actuaron en tal sentido:

Las reducidas instituciones locales - públicas estatales (administración local y espacios de representación) y de organizaciones sociales (acción comunal)junto con las oportunidades políticas que brindaba el entorno regional aportaron lo principal de las capacidades locales para responder a los desafíos del conflicto. ¿Cómo lo hicieron?

Las instituciones locales del Estado y la organización comunal actuaron de dos maneras para configurar la resistencia: a) permitieron la emergencia de liderazgos locales - en cabeza del grupo de funcionarios de la UMATA con trabajo capilar en el territorio y un buen reconocimiento colectivo- y b) aportaron la infraestructura logística (los espacios de representación política local al Concejo y a la Alcaldía, tanto como los espacios de convocatoria, discusión y decisión colectiva sobre las prioridades de inversión de las acciones comunales) para el montaje de un proyecto político capaz de ponerles límites a las intervenciones indeseadas de la guerrilla en la orientación de los recursos municipales y en las restricciones a la movilidad de los funcionarios por el territorio.

Además, los discursos de "soberanía popular" de las asambleas locales y de "participación ciudadana" del movimiento regional de resistencia a los efectos de la guerra que se desplegaba desde 1996 en el Oriente antioqueño, y el apoyo 
a las asambleas por la gobernación de Antioquia, como "asambleas constituyentes locales" (2000-2003), inspiraron los repertorios de resistencia de más largo aliento en Nariño, con los que lograron neutralizar las presiones de la guerrilla a líderes y administradores por los recursos públicos.

Así los espacios y acciones institucionales - por mínimos que sean, pero sostenidos en las décadas anteriores- aportaron una memoria que operó como recurso de la acción colectiva frente a los desafíos de la violencia. Conjugado con lo anterior, los contenidos de un discurso democrático novedoso, antes no experimentado pero ahora enarbolado y materializado en la acción de colectivos del entorno regional con los que se mantienen vínculos, aportaron horizontes de proyección mediante los cuales los resistentes locales imaginaron la posible y deseada transformación de su realidad.

Son entonces tres los factores del contexto histórico relacional que se combinaron en Nariño para posibilitar la resistencia: los reducidos espacios institucionales locales - tanto los que materializan el poder infraestructural del Estado como los que viabilizan los poderes colectivos de la sociedad- así como las oportunidades políticas del entorno. Lo anterior se concretó, en términos de la agencia, en una interacción de elementos del "iteración" (memoria del pasado) y de "evaluación práctica" (reflexividad sobre el presente) mediante los cuales los pobladores mostraron su capacidad de maniobrabilidad y transformación de las restricciones que el contexto imponía.

\subsection{Riosucio (Chocó)}

La resistencia en Riosucio se presenta en una localidad en la que las instituciones preexistentes no son legítimas ni eficaces. No existía una tradición de organización ni capacidades manifiestas en acciones colectivas por la defensa de derechos; tampoco una experiencia colectiva de institucionalidad sobre la cual apoyarse, pues las primeras organizaciones campesinas e indígenas apenas se habían constituido 13 años antes y solo habían adelantado, de manera muy incipiente y acompañada por el clero local, algunas acciones legales frente a las compañías madereras ${ }^{30}$. Los Consejos Comunitarios apenas estaban siendo divulgados como idea y como derechos. Y las instituciones estatales se reducían a la Alcaldía y una débil administración local-muy plegadas a la fuerza de los intereses privados de madereras, contrabandistas o grupos armados- $\mathrm{y}$ a entidades de orden regional y nacional como la Corporación Autónoma Regional para el Desarrollo Sostenible (Codechocó) con muy altos niveles de corrupción y el Batallón de Infantería de Marina No. 50 que cubría el control territorial por la vía fluvial del Atrato y sus afluentes.

¿Qué se necesitó para que la resistencia hubiera sido el resultado? La conjunción de cinco factores: la oferta de apoyo, acompañamiento y empoderamiento a la población por parte de un tercer actor-entidades eclesiásticas-; la memoria

30 Organización Campesina del Bajo Atrato -Ocaba- (creada por claretianos como manera de neutralizar influencia guerrillera en las acciones comunales y como manera de regionalizar la conciencia-discurso y práctica de los campesinos) y Cabildo Mayor Indígena del Bajo Atrato (Camizba). 
de confianzas, lazos y lealtades de la población a esos acompañamientos de la Iglesia; el carácter étnico de la población; la oportunidad política que brindó el marco jurídico de la recién expedida Ley 70 de 1993 sobre los Territorios Colectivos; y los aprendizajes que los líderes y las comunidades afrocolombianas despliegan con respecto a las maneras de hacer valer lo que simboliza su nueva autoridad como asociación de consejos comunitarios.

La oferta de apoyo proveniente de entidades eclesiásticas tiene raíces en la propia inserción histórica de estas en la región -los claretianos como misioneros durante todo el siglo XX, y las ONG (una jesuita y otra intereclesial) que habían fungido respectivamente como comisión verificadora y como acompañantes y empoderadores de la población vulnerada por el conflicto armado en el Urabá de los años de 1990-. Con el estallido de la confrontación armada en el Bajo Atrato esta oferta se potencia por el carácter étnico que tiene la población y el valor político especial que comporta. Es indudable que la intervención de estas entidades eclesiales acompañando a las comunidades desempeña un papel fundamental en la orientación y sostenibilidad en el tiempo de estas resistencias.

Para las comunidades no constituyó novedad este acompañamiento. La condición de exclusión económica, social y política ancestral les significó no contar con memorias sobre interacciones directas con instituciones del Estado y a cambio solo saber de la Iglesia católica que durante buena parte del siglo XX fue la única institución nacional educadora y orientadora. Esas memorias y lealtades facilitaron que, a su lado, y ante las restricciones que imponía el retorno de los desplazados en medio de la confrontación armada, los resistentes innovaran en materia de los repertorios de la acción: las formas de asentarse y moverse en el territorio, las redes de apoyo nacionales e internacionales que se formaron, el llamado a la justicia internacional para conminar al Estado.

Con el tiempo, se sumaron los aprendizajes de las comunidades sobre las maneras concretas y prácticas de afrontar la palabra y la acción para ponerles límites a las constantes presiones de los grupos armados en la vida cotidiana en el territorio. Esos aprendizajes tuvieron dos pilares: el desafío de los patrones con que en los tiempos pasados habían afrontado las presiones armadas, o lo que Emirbayer y Mische llamarían "reconfigurar los esquemas recibidos y generar posibles respuestas alternativas a las situaciones problemáticas que los confrontan" $(1998,984)^{31}$; y muy ligado con lo anterior, reconocer en la práctica, y reforzarlo como nuevo patrón de pensamiento y acción, el valor simbólico de la autoridad de los líderes comunitarios, fundado en el poder colectivo institucionalizado y reconocido hasta por las comandancias regionales y nacionales de los grupos armados.

31 Un ejemplo: "Me parece fundamental el hecho de que la gente que asume las riendas de un consejo comunitario... cuando uno tiene bien clarito este papel yo considero que esto ayuda mucho. Lo digo por mí, soy consciente que este trabajo, el final de uno es la muerte, ese es el pago, sea de la misma gente de uno o sea de los que no gustan de uno, eso lo tengo bien clarito en la cabeza y eso me ha permitido a mí llegar y hablarles a estos actores armados y decirles no, es que las cosas son de esta y esta manera también, o sea, se perdió el temor ya y entonces eso ayuda mucho, cuando ellos ven que uno comienza a gaguearles y que no tienen la película bien clara, entonces eso también" (Entrevista a Ernesto Ramírez, 2012). 
Así, en Riosucio - donde una confrontación violenta extrema por disputa entre actores armados se desarrollaba y donde las comunidades no contaban con experiencias previas de una institucionalidad estatal legítima y sostenida en el tiempo, ni con aprendizajes suficientes en el ejercicio de su ciudadanía- fueron los factores del contexto histórico relacional propios del lugar los que en conjunto y de manera combinada posibilitaron las resistencias (en plural, porque fueron de diferente tipo y orientación política): la intervención de actores eclesiales que acompañaron el proceso, las memorias que la población tenía sobre el papel de ese tipo de acompañamientos, el carácter étnico de la población que convocó ese acompañamiento, la oportunidad política que aportó la recién expedida Ley sobre los Territorios Colectivos de los afrocolombianos, y los aprendizajes manifiestos.

\subsection{San Pedro de Urabá}

ACOP fue el orden configurado en San Pedro de Urabá después de que los paramilitares impidieran la pretensión de las FARC de tener el control hegemónico del territorio y de que ayudaran a campesinos y a desmovilizados a canalizar la resistencia contra las FARC, enemigo acérrimo del ejército EPL.

Al quedarse a partir de mediados de los años de 1990 como único actor armado en ejercicio de control político, los paramilitares hicieron de San Pedro de Urabá el territorio de retaguardia para sus ejércitos, el corredor de comunicación entre el golfo de Urabá y el centro del país, el lugar estratégico para el control del tráfico de drogas y para la comunicación con el exterior. Este orden local sí muestra el caso típico al que Kalyvas (2008) alude cuando habla de la relación entre una población más proclive a colaborar con los armados que dominan su territorio cuando esta dominación no está siendo disputada por otro y hay una correlativa baja utilización de violencia.

¿Qué explica el acomodo de la población a la coerción de un ejército paramilitar ya asentado y con hegemonía en el territorio? En primer lugar, un débil poder infraestructural del Estado expresado en una mínima institucionalidad para atender asuntos públicos y del bienestar general, plegada a los escasos liderazgos que ofrecía el Partido Liberal y sus redes clientelares, así como a lealtades alternativas a otros poderes informales socialmente aceptados y legitimados -como el de la hacienda y en algunos casos el de la antigua insurgencia-. Esos patrones y comportamientos políticos locales daban por entendido el estrecho lugar y la escasa tradición y consolidación de la ley estatal como parámetro de orden y defensa de lo público. Este fue el amplio margen que encontraron los paramilitares para aprovechar en su favor la escasa estructura jurídica, política y material del Estado. Así, el control sobre la ejecución del gasto, la asignación de convenios y la definición de las partidas presupuestales pasó rápidamente a manos de los paramilitares ayudados por políticos y concejales. En el nuevo orden que se configuraba se acentuó por parte de la población esa tendencia a darles su lealtad y confianza a las autoridades a cambio de apoyo y solución a las necesidades vitales de los pobladores.

En consecuencia, el Estado local perdió el poco terreno que tenía al no disputarles su autoridad a estos nuevos poderes y antes bien, delegarles funciones como ocurrió con Asocomún, la ONG del paramilitarismo, nombrada para 
acompañar y verificar programas institucionales del calado de Familias Guardabosques. Apoyó la transformación posterior de Asocomún en empresa prestadora de servicios certificada (Epsagro) con injerencia en localidades vecinas (Necoclí) y trampolín para convertirse en una Organización Gestora Acompañante (OGA) con tentáculos administrativos en el norte de Urabá.

El modelo hacendatario fue un segundo elemento en juego. Este modelo, de tradición sabanera, representaba la coexistencia de la gran propiedad del hacendado y del campesinado bajo la forma de agregado y o arrendatario en tierras de la hacienda; encarnaba una compleja institución del mundo rural con raíces en el siglo XVI, un producto de la región determinante de la vida económica, social, cultural y la idiosincrasia de los pobladores. ¿Cómo se acomodó este modelo hacendatario al nuevo orden local? Los viejos hacendados no expulsados y sobrevivientes debieron ceder a las nuevas condiciones de seguridad paramilitar pagando una cuota obligatoria destinada a fortalecer la seguridad armada para prevenir nuevas incursiones de las FARC, pero también, debieron facilitar trabajadores de sus fincas para desarrollar las iniciativas paramilitares en cuanto a la mejora de la infraestructura vial, indispensable para facilitar el desplazamiento de los ejércitos paramilitares. Las obras beneficiaban la valorización de las tierras de los hacendados e incrementaban la competitividad ganadera (comunicación, comercialización con Montería, Turbo, Arboletes, Necoclí).

A pesar de la permanencia de algunos viejos propietarios bajo nuevas condiciones, fueron los paramilitares y narcotraficantes quienes reprodujeron, acentuándolo, el modelo hacendatario en condiciones "más patronales" y autoritarias a las precedentes, remplazando gran parte de los antiguos hacendados y reforzando el modelo en cuanto a la extensión de las haciendas, las formas culturales para manejarlas y el autoritarismo para controlarlas. Los campesinos aceptaron el cambio de los tradicionales hacendados por hacendados paramilitares paisas y vallunos narcotraficantes porque ofrecían oportunidades para acceder a la tierra y satisfacer parte de las viejas reivindicaciones rurales.

Un tercer elemento para entender cómo la población se acomodó y configuró un nuevo orden ACOP fue la experiencia colectiva campesina en la organización y movilización social y comunitaria que traía de su historia previa al dominio paramilitar ${ }^{32}$. A pesar del exterminio paramilitar de la red comunitaria socialmente institucionalizada por considerarla apoyo de la guerrilla, de asesinar a muchos de sus líderes y de doblegar sus formas de acción dictando nuevas maneras de actuación y procedimiento, la organización comunitaria preservó su espíritu y formas socioculturales de convites y mano prestada para recolectar recursos y hacer obras de beneficio colectivo. Tal espíritu y tal organización fueron revividos por aliento instrumental de hacendados y testaferros paramilitares

32 Nos referimos a la triple resistencia territorial representada en las guerrillas liberales contra el gobierno conservador de la década de 1950; en la formación de la guerrilla EPL creada y apoyada por exguerrilleros liberales y gente del lugar a fines del decenio de 1960 contra el Estado con un modelo de organización en juntas patrióticas replicado entre no combatientes bajo la forma de juntas veredales para el manejo de la vida cotidiana, y en las prácticas socialistas de los campesinos expulsados del Sinú seguidores de Vicente Adamo en la década de 1920. Las tres tradiciones se expresaron en la movilización por la tierra del decenio de 1970 bajo la línea dura de la Asociación Nacional de Usuarios Campesinos, ANUC. 
buscando apoyo comunitario para administrar sus haciendas y para apropiar el territorio de manera estratégica y compenetrada para el éxito del nuevo orden, apoyo campesino que se concretó en un proyecto asociativo común.

El modelo asociativo común de perfil privado de inspiración paramilitar denominado Asocomún, congregó tres actores para desarrollar el agro: al Estado para apalancar proyectos, al sistema o modelo hacendatario con sus empresas o fincas paramilitares para el préstamo o alquiler de tierras para producción de los campesinos, y al campesino para incorporar su saber y práctica organizativa como su capital de trabajo. El fin era desarrollar las organizaciones comunitarias para desarrollar el campo con asesoría técnica, insumos y facilidades ofrecidas por el Estado y los privados paramilitares, sobrepasando las viejas trabas a la condición de colonos sin tierra, y buscando combatir la desnutrición y distribuir los excedentes del agro. Difícilmente un campesino podía oponerse a un proyecto de tal magnitud que también beneficiaba a las otras partes (Estado y empresas paramilitares) y que auguraba éxitos para revertir las precarias condiciones de vida del campesinado en cuanto al arreglo de caminos, la limpieza de potreros, la seguridad alimentaria, la creación de cooperativas y asociaciones productivas y comerciales. Para los paramilitares significaba el control territorial en una zona estratégica de retaguardia nacional.

En suma, la configuración compleja de este nuevo orden paramilitar de San Pedro de Urabá tuvo en la institucionalidad pública estatal, la institucionalidad sociocultural hacendataria y las experiencias de acción y organización colectiva, tres pilares de apuntalamiento del proyecto paramilitar para la transformación del orden local. De esta configuración se destaca una agencia campesina que contiene el flujo del tiempo al incorporar experiencias del pasado en las decisiones del presente que buscan cambios a futuro. También la validez y fortaleza de un modelo cultural de tipo hacendatario sin el cual habría sido difícil configurarse una coerción política paramilitar como la que se instaló en Urabá.

\section{Conclusiones}

En contextos relacionales tan diversos como Nariño, Riosucio y San Pedro de Urabá se muestra que las agencias no pueden ser explicadas desde enfoques que solo enfaticen los factores de la coerción para explicar el tipo de agencia, ni tampoco explicaciones que privilegien unidimensionalmente unas condiciones previas y determinadas de la institucionalidad para explicar las posibilidades de la agencia presente. El análisis comparado de nuestros casos nos reafirma en la pertinencia de buscar siempre explicaciones complejas, esto es, de considerar la acción combinada de varios factores que en conjunto producen un resultado determinado.

Cuando se trata de explicar órdenes sociales o tipos de interacción entre actores armados y pobladores en contextos de confrontación armada, es conveniente considerar la acción explicativa de una pluralidad de factores, y la condición no unívoca de las interacciones que se establecen entre tipos de agencia y tipos de coerción. Nuestro enfoque permite abrir el abanico de posibilidades y mostrar que no se puede pensar en relaciones unicausales entre el tipo de coerción que establecen los actores armados y la agencia de los pobladores que la viven; que la agencia posible es diversa, así sean similares las condiciones de 
la coerción que se le contraponen o que la agencia puede ser de una misma especie, así sean muy diversas y hasta antagónicas las condiciones de la coerción con las que se interactúe.

\section{Referencias bibliográficas}

Arjona, Ana. Orden social y resistencia civil en conflictos armados, S/f. https://cpolitica.uniandes.edu.co/docs/descargar.php?f=./data/pdf/depto/seminario_2012/Orden.pdf (último acceso: 26 de abril de 2015).

Bourdieu, Pierre. Meditaciones Pascalianas. Madrid: Anagrama, 1999.

Caracol.com. Capturan al alcalde de Riosucio-Chocó, 26 de marzo de 2010. http:// www.caracol.com.co/noticias/judicial/por-parapolitica-capturan-al-alcaldede-riosucio-choco/20100326/nota/977595.aspx (último acceso: 26 de abril de 2015).

Cívico, Aldo. "No divulgar hasta que los implicados estén muertos". Las guerras de "Doblecero". Bogotá: Intermedio editores, 2009.

Comisión Intereclesial de Justicia y Paz, Banco de Datos. Tramoya: Derechos Humanos y Palma Aceitera en Jiguamiandó Curvaradó, 28 de abril de 2008. http://www.nocheyniebla.org/files/ul/casotipo/LaTramoya.pdf (último acceso: 26 de abril de 2015 ).

Defensoría del Pueblo. Resolución Defensorial No. 025 Sobre las violaciones masivas de los derechos humanos y desplazamiento forzado en la región del Bajo Atrato chocoano. Bogotá: Defensoría del Pueblo, octubre de 2002.

Del Gatto, Fillippo. La extracción maderera en el Chocó biogeográfico: el desafío de la gobernanza forestal en contextos sociales y políticos complejos. Documento preliminar para la discusión y comentarios. Cali: WWF-Colombia y Corpourabá, marzo de 2008.

Departamento Administrativo Nacional de Estadística (DANE). Boletín Censo general 2005. Perfil Riosucio Chocó, 2005a. https://www.dane.gov.co/files/cens02005/perfiles/choco/riosucio.pdf (último acceso: 27 agosto de 2014).

Departamento Administrativo Nacional de Estadística (DANE). Boletín Censo general 2005. Perfil Carmen del Darién, 2005b. http://www.dane.gov.co/files/ censo2005/perfiles/choco/carmen del darien.pdf (último acceso 27 agosto de 2014).

Elespectador.com. Funcionarios de Córdoba aceptaron nexos con El Alemán, 3 de agosto de 2012. http://www.elespectador.com/noticias/judicial/funcionariosde-cordoba-aceptaron-nexos-alias-el-aleman-articulo-365088 (última consulta: 23 marzo de 2015).

Eltiempo.com. Alcaldes frente al desorden público, 5 de enero de 1997. http:// www.eltiempo.com/archivo/documento/MAM-543541 (última consulta: 26 de abril de 2015).

Emirbayer, Mustafá y Ann Mische. «What is Agency?». American Journal of Sociology, Vol 13, nº 4 (enero 1998): 962-1.023.

García, Clara. «Resistencias. Análisis comparado de la acción colectiva frente a la guerra en Urabá y Oriente Antioqueño». NÓMADAS, n² 20, (abril 2004): 102-110.

García, Clara. «Violencia, resistencias y ciudadanía en localidades campesinas de Colombia. Comparaciones». Análisis Político, $\mathrm{n}^{\circ}$ 77, 2013: 39-56. 
García, Clara, Álvaro Guzmán, Clara Aramburo, Alba Rodríguez y Juan Domínguez. «Orden social y conflicto: resultados de una metodología comparada en nueve localidades de Colombia». Sociedad y economía, n 27 (julio-diciembre 2014a): 23-46.

García, Clara, Álvaro Guzmán, Clara Aramburo, Alba Rodríguez y Juan Domínguez. "Órdenes locales y conflicto armado. Una metodología comparada». Análisis Político, $\mathrm{n}^{\circ} 81$ (mayo-agosto 2014b): 3-17.

Kalyvas, Stathis. «Promises and Pitfalls of an Emerging Research Program: The Microdynamics of Civil War». En Order, Conflict, and Violence, editado por Stathis Kalyvas, Ian Shapiro y Tarek Masoud, 397-421. Nueva York: Cambridge University Press, 2008.

Observatorio de Procesos de Desarme, Desmovilización y Reintegración (ODDR). Visibilización mediática DDR caso Chocó. Abril 2008 - Junio 2010, agosto 2010. http://www.observatorioddr.unal.edu.co/visibilizaciones/visichoco_co_actualizacionagosto2011.pdf (última consulta: 26 de abril de 2014).

Radiosantafe.com. Acusan a alias El Alemán de la masacre de 451 personas, 04 de septiembre de 2009. http://www.radiosantafe.com/2009/09/04/acusan-aalias-el-aleman-de-la-masacre-de-451-personas/ (última consulta: 26 de abril de 2015).

Ragin, Charles. The Comparative Method. California: University of California, 1987.

Ragin, Charles. Fuzzy-Set Social Science. Chicago: University of Chicago Press, 2000. República de Colombia. Ley 70 de 1993 (agosto 27) Por la cual se desarrolla el artículo transitorio 55 de la Constitución Política. Bogotá: República de Colombia, 1993.

Semana.com. El "Führer" de Urabá, 29 de julio de 2006. http://www.semana.com/ nacion/articulo/el-fhrerde-uraba/80185-3 (última consulta: 19 de abril de 2015).

Semana.com. Denuncian control de paramilitares al comercio en Chocó, 18 de enero de 2010. http://www.semana.com/imprimir/111958 (última consulta: 26 de abril de 2015).

Tilly, Charles. Coerción, Capital y Los Estados europeos: 990-1990. Madrid: Alianza Editorial, 1994.

Vélez, Clara. Castaño marcó su muerte, 27 de agosto de 2006. http://www.elcolombiano.com/historico/castano_marco_su_muerte-OVEC_AO_4362485 (última consulta: 19 de abril de 2015).

Verdadabierta.com. Doce paramilitares fueron guías del ejército en la Operación Génesis: "El Alemán", s/f. http://www.verdadabierta.com/justicia-y-paz/2129 (última consulta: 19 de abril 2015).

\section{Entrevistas}

Entrevista a Julia Marín, exfuncionaria OXFAM para Bajo Atrato. Entrevistada por Clara Inés García y Clara Inés Aramburo, julio de 2012, Medellín, Colombia.

Entrevista a Ernesto Ramírez, líder de la Asociación de Consejos Comunitarios del Bajo Atrato (ASCOBA). Entrevistado por Clara Inés García y Clara Inés Aramburo, julio de 2012, Medellín, Colombia. 
Entrevista a líder de Asocomún de nombre reservado. Entrevistado por Clara Inés Aramburo y Clara Inés García, 30 de julio de 2010, San Pedro de Urabá, Colombia.

Entrevistas a gestores de la ONG, con nombre reservado. Entrevistados por Clara Inés Aramburo y Clara Inés García, julio de 2010, San Pedro de Urabá, Colombia.

Entrevistas a campesinos habitantes de veredas del municipio de Nariño, Antioquia. Entrevistados por Juan Camilo Domínguez, noviembre de 2012, municipio de Nariño, Antioquia. 